\title{
INFLUÊNCIA DO pH NA LIBERAÇÃO DE CÉLULAS PROBIÓTICAS ENCAPSULADAS EM ÁGAR-ÁGAR
}

ELISA LAURENTI * SANDRA GARCIA **

O objetivo deste estudo foi analisar a resistência do probiótico livre - Saccharomyces cerevisiae - e sua liberação sob diferentes valores de $\mathrm{pH}(4,5,6,0$ e 7,5) e tempos (5, 30 e $50 \mathrm{~min})$ quando encapsulado em ágar-ágar, além de avaliar a micro e a macro estrutura das esferas. O probiótico livre mostrou-se resistente em todo o período de avaliação, apresentando média de 93,6 \% de viabilidade. A levedura encapsulada em ágar-ágar foi gradualmente liberada das esferas, com média de $86,6 \%$ de células difundidas para o meio externo nas diferentes soluções tampão. As inúmeras fissuras e poros na matriz da esfera, observadas pelas microimagens, o intumescimento das cápsulas em meio aquoso e a concentração intracapsular empregada podem ter comprometido o total aprisionamento das células no interior da cápsula. As esferas foram fisicamente resistentes, pois não se solubilizaram e se mantiveram intactas durante o procedimento. Conclui-se que o ágar-ágar não constitui material encapsulante adequado para conferir liberação controlada do agente probiótico nas condições experimentais propostas neste estudo.

PALAVRAS-CHAVE: HIDROCOLÓIDE; LEVEDURA; LIBERAÇÃO CONTROLADA; MICROSCOPIA ELETRÔNICA DE VARREDURA; Saccharomyces cerevisiae.

* Mestre em Ciência e Tecnologia de Alimentos, Universidade Estadual de Londrina (UEL), Londrina, PR (e-mail: elisalaurenti@zootecnista.com.br).

** Doutora em Ciência de Alimentos, Docente, Departamento de Ciência e Tecnologia de Alimentos, (UEL), Londrina, PR (e-mail: sgarcia@uel.br). 


\section{INTRODUÇÃO}

A microencapsulação foi muito utilizada no passado para mascarar o sabor desagradável de certos ingredientes ou simplesmente para converter líquidos em sólidos. No entanto, o estudo sobre a liberação controlada do ingrediente encapsulado em lugar específico e hora determinada tem sido cada vez mais discutido, pois pode melhorar a eficácia dos aditivos alimentares, ampliar seu campo de aplicação e assegurar a dosagem ideal. Portanto, essa técnica pode originar ingredientes totalmente novos e com propriedades incomparáveis (GOUIN, 2004).

Define-se a microencapsulação como processo de empacotamento de materiais sólidos, líquidos ou gasosos em cápsulas extremamente pequenas, as quais podem liberar seu conteúdo de forma controlada e sob condições específicas (FÁVARO-TRINDADE, PINHO e ROCHA, 2008). Trata-se de alternativa promissora para a solução de grande parte dos problemas encontrados pela indústria para o desenvolvimento de novos alimentos probióticos. Na forma encapsulada, o probiótico apresenta proteção contra condições adversas do ambiente como, baixos valores de $\mathrm{pH}$, temperatura, umidade e a presença de oxigênio (BOSCARIOLI, 2010). Vários mecanismos podem ser utilizados para desencadear a liberação do agente ativo, como a mudança de pH, estresse mecânico, temperatura, atividade enzimática e tempo, entre outros (SUSKOVIK et al., 2001.

O aprisionamento de Saccharomyces cerevisiae em matrizes poliméricas tem sido utilizado para diversas finalidades, sendo alcançado mediante distintos métodos e materiais encapsulantes. Entretanto, ainda não foi pesquisado com a finalidade de promover a liberação controlada. A encapsulação de leveduras é pouco justificada, devido à resistência natural do micro-organismo em condições ambientais adversas. Essa propriedade tornou-se o principal fator de estudos de liberação controlada de células encapsuladas, visando garantir resultados confiáveis durante processos de simulação gastrointestinal, pois micro-organismos sensíveis não sobrevivem a determinadas fases do procedimento, diminuindo a contagem e dificultando a interpretação dos resultados.

A seleção da técnica de microencapsulação e de materiais encapsulantes são interdependentes, regendo-se pelas propriedades físicas e químicas do núcleo e dos materiais de revestimento para a aplicação almejada (DESAI e PARK, 2005). A encapsulação de leveduras constitui processo particularmente complexo, pois o micro-organismo aumenta a viscosidade do material encapsulante e produz gás durante o processo, impossibilitando a aplicação do probiótico em grandes concentrações e em determinados métodos de microencapsulação e materiais de parede.

O uso de biopolímeros como materais encapsulantes tem apresentado crescimento, devido às muitas possibilidades lucrativas de aplicação industrial (OKOJIE, OSUIDE e AIGBOKHIAN 2010). A propriedade biodegradável dos polímeros naturais torna-se especialmente conveniente na liberação do material encapsulado em determinado momento e/ou local no corpo (CHEN, XU e WANG 2006). Os registros históricos apontam que o ágar, ficocolóide de utilização mais antiga, foi o primeiro a ser usado na indústria alimentícia na forma de géis e em diversas outras aplicações industriais, como aditivos em alimentos.

O objetivo deste estudo foi avaliar a resistência do probiótico livre Saccharomyces cerevisiae e sua liberação sob diferentes valores de pH e tempo quando encapsulado em ágar-ágar, além de avaliar a micro e a macro estrutura das esferas durante o processo.

\section{MATERIAL E MÉTODOS}

A levedura viável desidratada (Saccharomyces cerevisiae) foi obtida do produto 
comercial Biosaf SC-47, produzido por Lesaffre - Saf Agri Brasil. A técnica de imobilização do probiótico $(10 \% \mathrm{p} / \mathrm{v})$ em cubos de ágar-ágar foi adaptada do modelo proposto por Behera et al. (2010). Sumariamente, a solução composta por 4 \% (p/v) ágar-ágar foi esterilizada em autoclave por 15 minutos a $121{ }^{\circ} \mathrm{C}$ e estabilizada em banho-maria até atingir a temperatura de $42{ }^{\circ} \mathrm{C}$. Ajustou-se o pH para valor de 6,6 para posterior incorporação e homogeneização do probiótico por meio de mixer (Philips RI1341). A mistura foi rapidamente vertida em recipiente de acrílico $(20,5 \mathrm{~cm} \times 14,5 \mathrm{~cm})$ e mantida sob refrigeração a $4{ }^{\circ} \mathrm{C}$ por 2 horas para solidificar. O bloco obtido foi cortado igualmente em cubos de $5 \mathrm{~mm}^{3}$, em cortador manual, e redistribuídos novamente nos recipientes de acrílico para se efetuar a secagem em estufa com circulação de ar a $45^{\circ} \mathrm{C}$ por 48 horas.

As cápsulas obtidas e o probiótico livre foram submetidos a diferentes soluções tampão, pH 4,5 (tampão citrato-fosfato 0,05 M 0,1 M), 6,0 (tampão fosfato 0,05 M) e 7,5 (tampão fosfato $0,05 \mathrm{M}$ ), retirando-se alíquotas nos tempos 5, 30 e 60 minutos para realizar a contagem das células. Nos ensaios, realizados em triplicata para cada valor de $\mathrm{pH}$, foram usados 5 gramas de amostra em $45 \mathrm{~mL}$ de solução tampão, agitados em shaker a $37^{\circ} \mathrm{C}$ e $150 \mathrm{rpm}$, conforme a metodologia proposta por Liserre, Ré e Franco (2007). Possíveis alterações na estrutura das esferas durante o procedimento foram monitoradas por fotografias ópticas (Sony DSCW530).

O probiótico encapsulado e livre foi analisado em relação a sua liberação das cápsulas e viabilidade, respectivamente, nas diferentes soluções tampão e tempos de avaliação. A contagem das Unidades Formadoras de Colônia (UFC) de Saccharomyces cerevisiae, por grama de amostra, foi realizada de acordo com a metodologia empregada por Guillou et al. (2003). As alíquotas foram semeadas em profundidade em ágar extrato de levedura glicose cloranfenicol (YGC) (Becton Dickinson \& Co.) e incubadas aerobicamente a $25^{\circ} \mathrm{C}$ por 96 horas. Cada tratamento foi avaliado em triplicata, sendo as diluições de cada repetição, plaqueadas em duplicata para se efetuar a média da contagem das colônias. A liberação ou a viabilidade foram representadas em porcentagem, utilizando-se a fórmula prescrita por Pennacchia et al. (2008):

Liberação ou Viabilidade $(\%)=\frac{\mathrm{Cf}}{\mathrm{Ci}} \times 100$

Em que:

$\mathrm{Cf}=$ contagem $\left(\log \mathrm{UFC} \cdot \mathrm{g}^{-1}\right)$ após o processo e $\mathrm{Ci}=$ contagem $\left(\log \mathrm{UFC} \cdot \mathrm{g}^{-1}\right)$ antes do processo.

Para realizar a contagem inicial das células contidas nas cápsulas foi proposto homogeneizar as amostras previamente, triturando $5 \mathrm{~g}$ de amostra em $45 \mathrm{~mL}$ de água peptonada estéril $\left(45^{\circ} \mathrm{C}\right)$, utilizando homogeneizador tipo turrax (Marconi, MA-102) por 30 segundos, como descrito por Annan, Borza e Truelstrup (2008).

Para analisar a microestrutura das esferas por Microscopia Eletrônica de Varredura (MEV) aplicou-se a metodologia sugerida por Reid et al. (2005) com algumas modificações. As esferas foram fixadas em glutaraldeído $2 \% / 0,1 \mathrm{M}$ tampão fosfato $(\mathrm{pH} 7,2)$ por 1 hora em temperatura ambiente, fraturadas em nitrogênio líquido e mantidas na mesma solução over night. No dia seguinte, foram submetidas a mais 3 lavagens de 15 minutos em tampão fosfato e, posteriormente, mantidas em solução de ósmio 1 \%/0,1 M tampão fosfato por 1 hora sem iluminação, sendo lavadas 3 vezes em tampão fosfato por 15 minutos e desidratadas gradualmente em etanol 70, 80, 90 e $100 \%$ por período total de 1 hora e 55 minutos. Por fim, as esferas mantidas em álcool $100 \%$ foram secas em ponto crítico (BAL-TEC, CPD 030), recobertas com ouro (BAL-TEC, SCD 050) e observadas em microscópio eletrônico de varredura (FEI QUANTA-200, Phillips) em alto vácuo e tensão (20 kV).

Os resultados de liberação da levedura encapsulada e a sua viabilidade quando livre em 
função do tempo e do pH foram submetidos à análise de variância, seguido por comparação de médias pelo teste de Tukey a $1 \%$ de probabilidade, usando-se o pacote computacional SISVAR, Sistema de Análise de Variância para Dados Balanceados (FERREIRA, 2007).

\section{RESULTADOS E DISCUSSÃO}

O número de células viáveis do probiótico livre em função do pH e tempo está demonstrado na Tabela 1. A análise dos resultados sugere que a levedura, Saccharomyces cerevisiae, sofre a ação do pH 6,0 e 7,5 em tempos distintos, uma vez que foram encontradas diferenças significativas na contagem durante o processo. No entanto, as médias das contagens nas soluções tampão foram significativamente semelhantes, pontuando que a acidez não influenciou a sobrevivência do probiótico (média geral de viabilidade de 93,6 \%) e ratificando a resistência da levedura nas condições propostas. Convém ressaltar que o fator responsável pela queda de $6,4 \%$ na viabilidade foi o pH. Segundo Rajkowska e Kunicka-Styczynska (2010), o pH pode influenciar o crescimento de leveduras, uma vez que diferentes cepas são tolerantes às enzimas e sais biliares.

TABELA 1 - VIABILIDADE DO PROBIÓTICO Saccharomyces cerevisiae (\% \pm DESVIO PADRÃO) NOS DIFERENTES VALORES DE pH E DE TEMPO

\begin{tabular}{|c|c|c|c|}
\hline \multirow{2}{*}{$\begin{array}{c}\text { TEMPO } \\
\text { (min) }\end{array}$} & \multicolumn{3}{|c|}{ VIABILIDADE (\%) } \\
\hline & pH 4,5 & pH 6,0 & pH 7,5 \\
\hline 5 & $92,52 \pm 2,9^{\mathrm{a}}$ & $91,13 \pm 0,69^{b}$ & $87,25 \pm 1,05^{b}$ \\
\hline 30 & $96,11 \pm 0,13^{\mathrm{a}}$ & $95,72 \pm 0,92^{a}$ & $90,33 \pm 0,81^{b}$ \\
\hline 60 & $97,09 \pm 2,25^{a}$ & $96,79 \pm 0,90^{a}$ & $95,39 \pm 0,77^{a}$ \\
\hline Média e CV (\%) & 95,24 a* $(2,25)$ & $94,55^{a *}(0,89)$ & $90,99 a *(0,97)$ \\
\hline
\end{tabular}

abc Médias na mesma coluna seguidas por diferentes letras minúsculas são significativamente diferentes ( $p<0,01)$.

$a_{c}^{*}$ Médias na mesma linha seguidas por diferentes letras minúsculas e asterisco são significativamente diferentes ( $\left.p<0,01\right)$. $\mathrm{CV}=$ Coeficiente de variação.

A tolerância ao $\mathrm{pH}$ deve-se aos dois tipos de anti-transportadores de $\mathrm{Na}^{+} / \mathrm{H}^{+}$da levedura, Nha1p e a Nahx1p, que estão localizados na membrana plasmática e no compartimento pré-vacuolar endosomal, respectivamente. Essas proteínas catalisam o intercâmbio de cátions monovalentes $\left(\mathrm{Na}^{+}, \mathrm{K}^{+}\right.$e $\left.\mathrm{H}^{+}\right)$através das membranas de tal modo que regulam as concentrações de cátions e pH em nível citoplasmático e de organelas. Outro possível mecanismo de regulação seria a ATPase, localizada na membrana citoplasmática, criando gradiente eletroquímico de prótons que conduz ao transporte secundário de solutos, que está envolvido na manutenção do pH perto da neutralidade (RUBIO et al., 2008).

Pennacchia et al. (2008) isolaram 22 cepas de Saccharomyces cerevisiae de diferentes matrizes alimentícias (queijos, vinhos e embutidos cárneos curados) e determinaram, in vitro, 
a sobrevivência das leveduras após a passagem pelo trato gastrointestinal. A simulação inicial foi realizada em $\mathrm{pH} 2,5$ por 2,5 horas a $37^{\circ} \mathrm{C}$ e alcançaram viabilidade média de $95,35 \%$. Porém, quando adicionaram sais biliares $(0,3 \%)$ e pancreatina $(0,1 \%)$ à solução inicial que foi incubada por 5 horas, apenas 3 cepas apresentaram sobrevivência maior que $90 \%$, indicando que a escolha da cepa é determinante na seleção do micro-organismo probiótico.

A levedura Saccharomyces cerevisiae (Biosaf SC-47, Lesaffre - Saf Agri Brasil) submetida a condições gastrointestinais simuladas apresentou sobrevivência de $94 \%$, conforme Laurenti (2011). O fator primordial que conferiu a queda de $6 \%$ na viabilidade do microorganismo foi o pH ácido, pois o aumento do $\mathrm{pH}$ e a adição de sais biliares (oxgall) e enzimas (lipase, pepsina e pancreatina) não alterou a contagem até o término da simulação.

Segundo Glicksman (1969), a sensibilidade das cápsulas de ágar-ágar ao meioácido se explica pela diminuição da força de gel que pode ser intensificada com o decréscimo do pH. Conforme Landim (2008)o desafio está em desenvolvermateriaisencapsulantesqueresistamaopHácidoesedesintegrem empH levemente básico paraqueas células sejam liberadas, em sua maior parteno intestino, porquanto a maioria dos gêneros probióticos utilizados não sobrevivem no trato gastrointestinal superior.

O número de células liberadas das esferas, quando submetidas às diferentes soluções tampão e variações de tempo, está descrito na Tabela 2, indicando que as porcentagens foram significativamente diferentes nas soluções de pH 6,0 e 7,5. O conteúdo encapsulado foi gradualmente liberado da esfera no decorrer do processo, explicando os menores valores iniciais. Não foram encontradas diferenças significativas entre as médias nos diferentes valores de $\mathrm{pH}$, apontando que a acidez não influenciou a liberação das células e totalizando a média geral de 86,6 \% de difusão do material encapsulado para o meio externo.

\section{TABELA 2 - LIBERAÇÃO DO PROBIÓTICO Saccharomyces cerevisiae DAS CÁPSULAS COMPOSTAS POR ÁGAR-ÁGAR NOS DIFERENTES VALORES DE PH E DE TEMPO}

\begin{tabular}{c|c|c|c}
\hline \multirow{2}{*}{$\begin{array}{c}\text { TEMPO } \\
(\text { min) }\end{array}$} & \multicolumn{3}{|c}{ LIBERAÇÃO (\%) } \\
\cline { 2 - 4 } & $\mathbf{p H ~ 4 , 5}$ & $\mathrm{pH} \mathrm{6,0}$ & $\mathrm{pH} \mathrm{7,5}$ \\
\hline 5 & $85,77 \pm 3,58^{\mathrm{a}}$ & $84,09 \pm 0,84^{\mathrm{b}}$ & $79,39 \pm 1,27^{\mathrm{b}}$ \\
\hline 30 & $85,72 \pm 7,48^{\mathrm{a}}$ & $89,66 \pm 1,11^{\mathrm{a}}$ & $83,12 \pm 0,99^{\mathrm{b}}$ \\
\hline 60 & $91,32 \pm 2,73^{\mathrm{a}}$ & $90,96 \pm 1,09^{\mathrm{a}}$ & $89,26 \pm 0,94^{\mathrm{a}}$ \\
\hline Média e CV (\%) & $\mathbf{8 7 , 6 1}{ }^{\mathrm{a*}}(\mathbf{5 , 7 5 )}$ & $\mathbf{8 8 , 2 3}{ }^{\text {a* }}(\mathbf{1 , 1 6 )}$ & $\mathbf{8 3 , 9 2}{ }^{\text {a* }}(\mathbf{1 , 2 8})$ \\
\hline
\end{tabular}

abc Médias na mesma coluna seguidas por diferentes letras minúsculas são significativamente diferentes ( $p<0,01)$. $a^{a} c^{*}$ Médias na mesma linha seguidas por diferentes letras minúsculas e asterisco são significativamente diferentes ( $\left.p<0,01\right)$. $\mathrm{CV}=$ Coeficiente de variação.

Observando os valores de liberação do probiótico encapsulado e de viabilidade do probiótico livre, nos diferentes valores de $\mathrm{pH}$ e tempo, nota-se que ambos mostraram basicamente a mesma tendência. As células encapsuladas apresentaram contagem menor no início do 
processo, pois ainda estavam sendo liberadas do interior da esfera, explicando o aumento gradual na contagem no decorrer do tempo. Praticamente todo o conteúdo encapsulado foi difundido para o meio externo, aprisionando apenas pequena porção do material incorporado inicialmente. As curvas demonstraram comportamento semelhante ao das células livres, como observado na Figura 1.

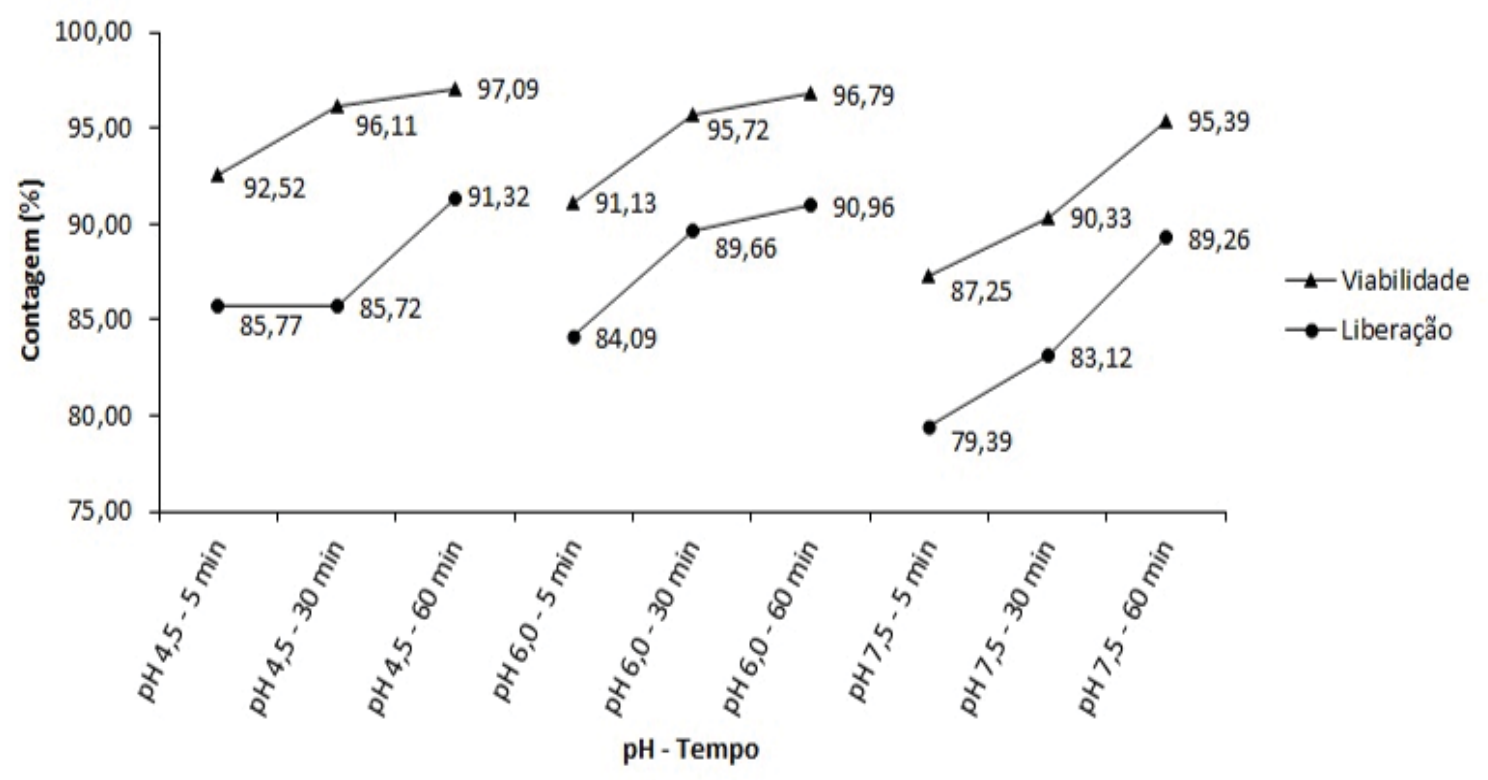

\section{FIGURA 1 - LINHA DE TENDÊNCIA DA VIABILIDADE DO PROBIÓTICO LIVRE E LIBERAÇÃO DAS CÉLULAS ENCAPSULADAS EM ÁGAR-ÁGAR A DIFERENTES VALORES DE $\mathrm{PH}$ E TEMPO}

Os fatores que podem influenciar o controle da taxa de liberação de agente bioativo são: i) a expansão do volume de microcápsulas, devido à hidratação; ii) a permeabilidade da cápsula; iii) a área de superfície em contato com o meio aquoso e iv) a concentração intracapsular do agente diluído dentro da cápsula (CORREA, 2003). Essas variáveis poderiam explicar parte dos fenômenos ocorridos durante os experimentos neste trabalho, uma vez que o ágar-ágar absorve quantidade de água equivalente a 20 vezes o seu próprio peso, forçando a saída do material encapsulado para o meio externo. O volume da cápsula aumentou nas soluções tampão, porém não alterou a forma física das esferas que continuaram íntegras e intumescidas em sua maior parte até o término do processo (Figura 2), indicando que as esferas são fisicamente resistentes às condições de pH e agitação por longos períodos de tempo. Segundo Nascimento et al. (2011) para que ocorra a difusão do material encapsulado, o polímero deve se intumescer (por exemplo, com água), o que leva ao abaixamento da temperatura de transição vítrea, tornando o material mais plástico e desse modo o núcleo pode se difundir para o meio externo.

A relação material encapsulante e encapsulado de 1:2, respectivamente, também pode ter comprometido o total aprisionamento das células em meio aquoso (Figura 3), evidenciando a insuficiência de material encapsulante mediante a elevada quantidade de leveduras aprisionadas. Behera et al. (2010) imobilizaram a levedura com sucesso pelo método de extrusão, homogeneizando as células em solução de $2 \%(\mathrm{p} / \mathrm{v})$ de alginato de sódio e solidificando as gotas em cloreto de cálcio $0,1 \mathrm{M}$. Tais autores utilizaram aproximadamente $5 \%(\mathrm{p} / \mathrm{v})$ da levedura, concentração que pode ter sido fundamental para a eficácia do método.

A presença de fissuras e poros na extensão da esfera, demonstrada na Figura 4, são características físicas que também podem ter influenciado substancialmente a difusão das células para o meio externo. 


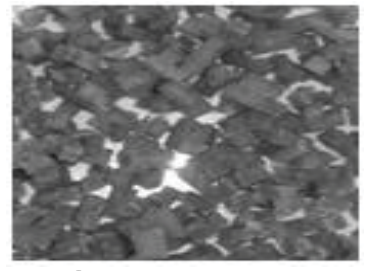

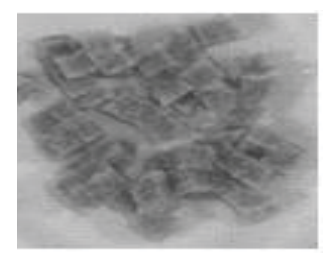

pH 4,5

$5 \mathrm{~min}$

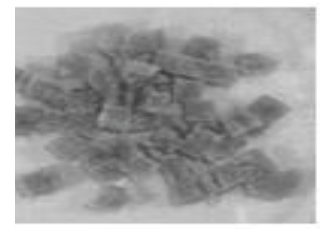

$\mathrm{pH} \mathrm{6,0}$

$5 \mathrm{~min}$

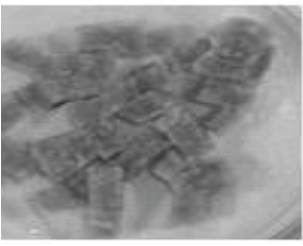

$\mathrm{pH} 7,5$

$5 \mathrm{~min}$
Cápsula seca



$\mathrm{pH} 4,5$

$30 \mathrm{~min}$

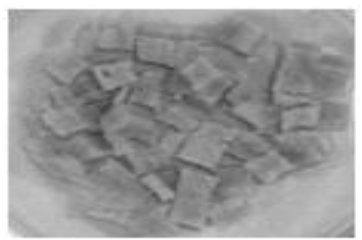

$\mathrm{pH} \mathrm{6,0}$

$30 \mathrm{~min}$

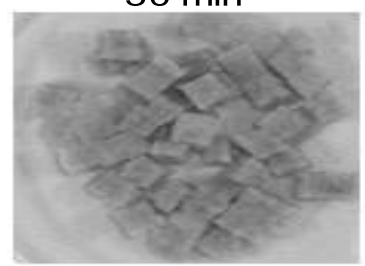

$\mathrm{pH} 7,5$

$30 \mathrm{~min}$

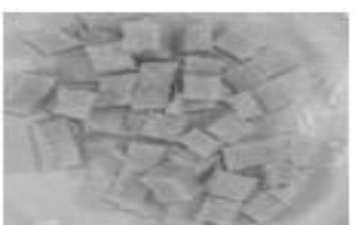

$\mathrm{pH} 4,5$

$60 \mathrm{~min}$



pH 6,0

$60 \mathrm{~min}$

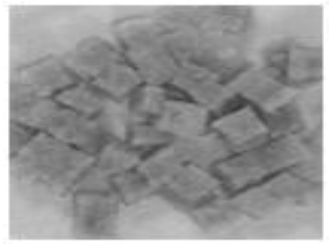

$\mathrm{pH} 7,5$

$60 \mathrm{~min}$

FIGURA 2 - ESFERAS DE Saccharomyces cerevisiae ENCAPSULADAS EM ÁGAR-ÁGAR E SUBMETIDAS A DIFERENTES SOLUÇÕES TAMPÃO E VARIAÇÕES DE TEMPO

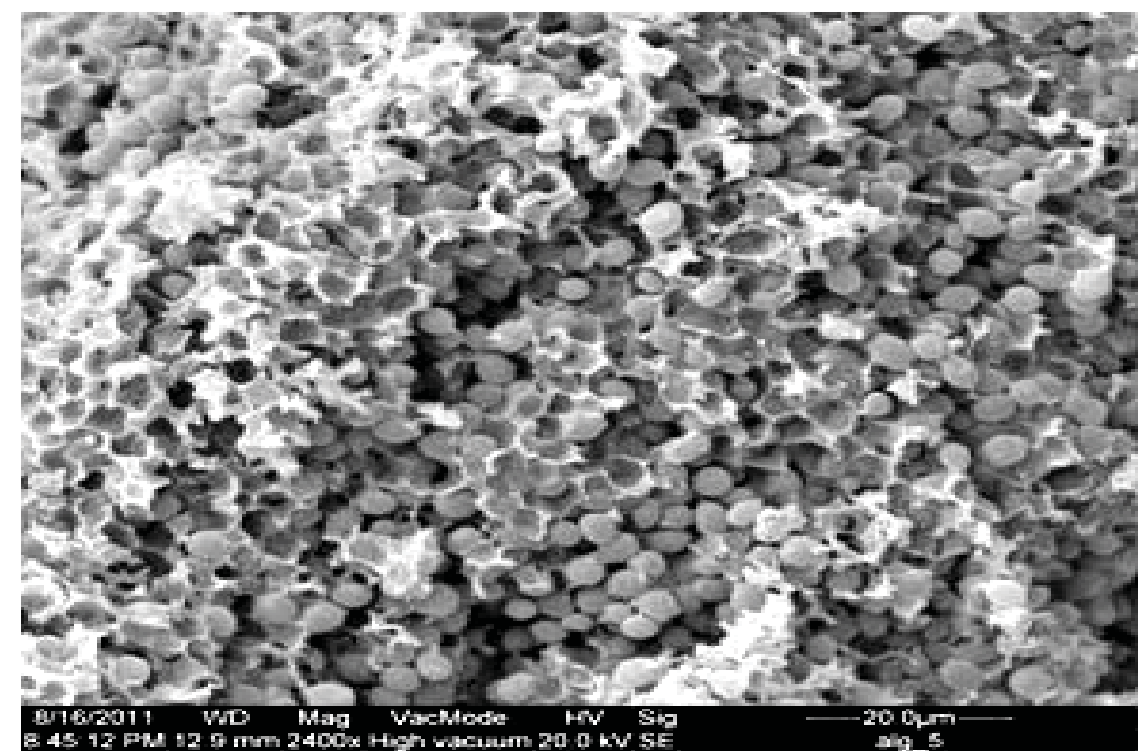

FIGURA 3 - NÚCLEO DA ESFERA DE LEVEDURA ENCAPSULADA EM ÁGAR-ÁGAR VISUALIZADO POR MEIO DE MICROSCOPIA ELETRÔNICA DE VARREDURA COM AUMENTO DE 2400 VEZES 
A resistência do micro-organismo em estudo em ambientes críticos pode ser ótima ferramenta para pesquisas da liberação controlada do núcleo de microcápsulas, originando respostas mais confiáveis. O desprendimento das células, nos diferentes períodos e valores de $\mathrm{pH}$, pode ser avaliado sem que ocorram respostas subestimadas, pois as leveduras sobrevivem durante todo o processo. Segundo Liserre, Ré e Franco (2007) estudos sobre a sobrevivência de bactérias probióticas em soluções tampão podem levar a resultados errôneos, porque o potencial de sobrevivência pode ser subestimado. Ressaltaram ainda que os resultados da literatura sobre a eficácia de encapsulamento para proteção de culturas probióticas são controversos e existe alta variação nos parâmetros avaliados, o que torna difícil a identificação do melhor procedimento de microencapsulação.
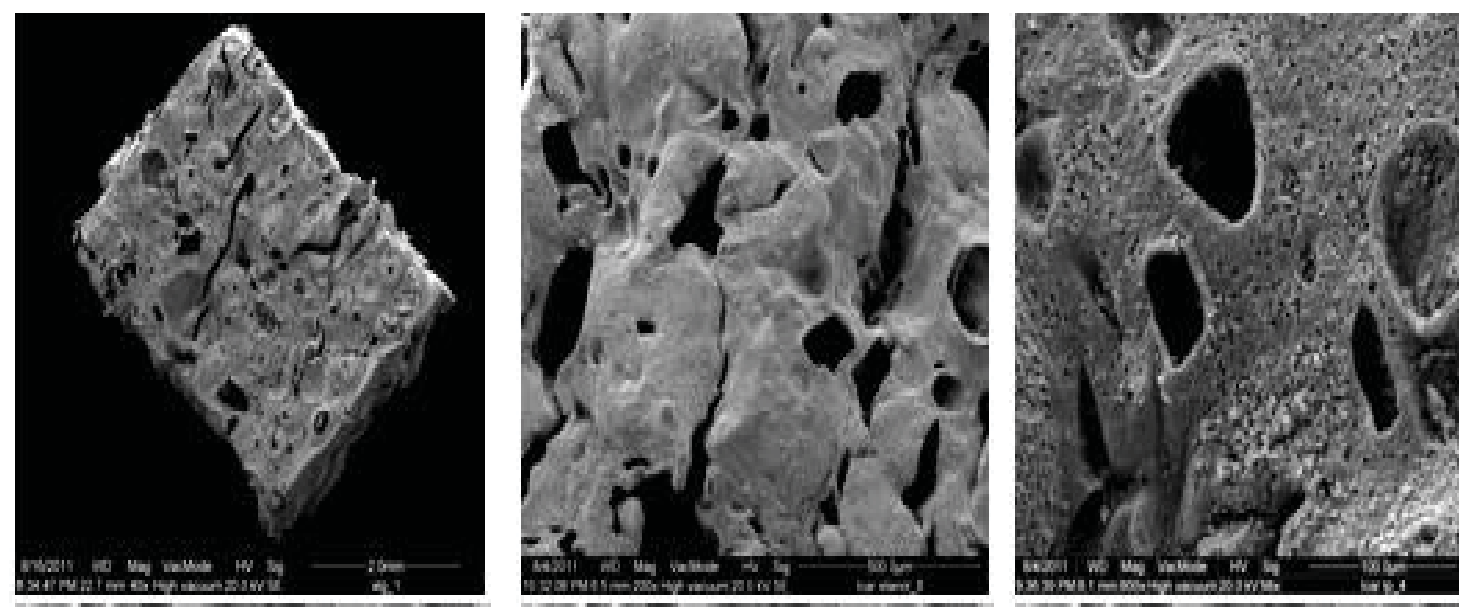

\section{FIGURA 4 - ESFERA DE Saccharomyces cerevisiae OBSERVADA POR MICROSCOPIA ELETRÔNICA DE VARREDURA COM AUMENTO DE 50, 200 E 800 VEZES, RESPECTIVAMENTE}

\section{CONCLUSÃO}

Conclui-se que o ágar-ágar não é material encapsulante adequado para conferir liberação controlada do agente probiótico, Saccharomyces cerevisiae, nas condições experimentais propostas neste estudo.Vale ressaltar que a levedura livre mostrou-se resistente em todos os valores de $\mathrm{pH}$ e tempos avaliados, sendo indicada para estudos em soluções tampão com várias graduações de acidez.

Sugere-se a aplicação de revestimento sobre as esferas e testes com diferentes probióticos em estudos futuros.

\section{ABSTRACT}

\section{INFLUENCE OF pH ON RELEASE OF PROBIOTIC CELLS ENCAPSULATED IN AGAR}

The objective of this study was to evaluate the resistance of free probiotic (Saccharomyces cerevisiae) and its release under different $\mathrm{pH}$ values (4.5, 6.0 and 7.5) and times (5, 30 and 50 minutes) when encapsulated in agar-agar, and also to observe the structure using micro and macro images. The free probiotic showed resistance throughout the evaluation period, with an average of $93.6 \%$ viability. The yeast encapsulated in agar-agar was gradually released from the spheres, with an average of $86.6 \%$ of cells spread to the outside in different buffer solutions. The number of cracks and pores in the matrix of the spheres, seen by micro images, the swelling of the capsules in an aqueous medium, and the intracapsular concentration that was employed may have compromized the total cell entrapment within the capsule. The spheres were physically resistant, because they did not solubilize and they remained intact during the procedure. It was concluded that agar-agar was not 
a suitable encapsulating material to impart the controlled release of the probiotic in the experimental conditions of this study.

KEY-WORDS: CONTROLLED RELEASE; HYDROCOLLOIDS; Saccharomyces cerevisiae; SCANNING ELECTRON MICROSCOPY; YEAST.

\section{REFERÊNCIAS}

1 ANNAN, N.T.; BORZAA.D.; TRUELSTRUP, L.H. Encapsulation in alginate-coated gelatin microspheres improves survival of the probiotic Bifidobacterium adolescentis 15703T during exposure to simulated gastro-intestinal conditions. Food Res. Int., v.41, n.2, p.184-193, 2008.

2 BEHERA, S.; KAR, S.; MOHANTY, R.C.; RAY, R.C. Comparative study of bio-ethanol production from mahula (Madhuca latifolia L.) flowers by Saccharomyces cerevisiae cells immobilized in agar agar and Ca-alginate matrices. Appl. Energ., v. 87, p. 96-100, 2010.

3 BOSCARIOLI, M.P. Influência de prebióticos na encapsulação de bactérias probióticas adicionadas em sorvete. 2010. 72 f. Dissertação (Mestrado em Engenharia de Processos Químicos e Bioquímicos) - Escola de Engenharia Mauá, Instituto Mauá de Tecnologia, São Caetano do Sul, 2010.

4 CHEN, H.H.; XU, S.; WANG, Z. Gelation properties of flaxseed gum. J. Food Eng., v.77, p.295-303, 2006.

5 CORREA, R. M. Preparo e caracterização de microcápsulas obtidas por polimerização iônica para alimentação de larvas de peixe. 2003. 178 f. Dissertação (Mestrado em Alimentos e Nutrição) - Faculdade de Engenharia de Alimentos, Universidade Estadual de Campinas, Campinas, 2003.

6 DESAI, K.G.H.; PARK, H.J. Recent developments in microencapsulation of food ingredients. Dry Technol., v.23, p.13611394, 2005.

7 FÁVARO-TRINDADE, C.S.; PINHO, S.C.; ROCHA, G.A. Microencapsulação de produtos alimentícios. Braz. J. Food Technol., v.11, n.2, p 103-112, 2008.

8 FERREIRA, D.F. Sisvar: sistema de análise de variância para dados balanceados. Versão 5.1 Build 72. Lavras: DEX/ UFLA, 2007.

9 GLICKSMAN, M. Gum technology in food industry. New York: Academic Press, 1969.

10 GOUIN, S. Microencapsulation: industrial appraisal of existing technologies and trends. Trends Food Sci. Technol., v.15, p.330-347, 2004.

11 GUILLOU, S.; BESNARD, V.; EL-MURR, N.; FEDERIGHI, M. Viability of Saccharomyces cerevisiae cells exposed to lowamperage electrolysis as assessed by staining procedure and ATP content. Int. J. Food Microbiol., v.88, n.1, p.85-89, 2003.

12 LANDIM, E.M.C. Obtenção, caracterização e avaliação da estabilidade de pigmentos naturais microencapsulados. 2008. 80 f. Dissertação (Mestrado em Ciência e Tecnologia de Alimentos) - Universidade Federal do Ceará, Fortaleza, 2008.

13 LAURENTI, E. Materiais encapsulantes naturais na obtenção de esferas de S. cerevisiae para incorporação em ração extrusada de frangos de corte. 2011. 102 f. Dissertação (Mestrado em Ciência e Tecnologia de Alimentos) Universidade Estadual de Londrina, Londrina, 2011.

14 LISERRE, A.M.; RÉ, M.I.; FRANCO, B.D.G.M. Microencapsulation of Bifidobacterium animalis subsp. lactis in modified alginate-chitosan beads and evaluation of survival in simulated gastrointestinal conditions. Food Biotechnol., v.21, p.116, 2007.

15 NASCIMENTO, R.L.; QUEIROZ, A.A.A.; RIBELA, M.T.C; CAMILLO, M.A.P. Sistemas de liberação controlada de crotoxina a partir de matriz polimérica: uma alternativa para o tratamento de câncer. R. Ciênc. Saúde, v.1, n. 2, p. 42-47, 2011.

16 OKOJIE, V.U.; OSUIDE, M.O.; AIGBOKHIAN, A. A study of some physico-chemical characteristics of cashew tree exudate Anacardium occidentale. Adv. in Nat. Appl. Sci., v.8, p.259-263, 2010.

17 PENNACCHIA, C.; BLAIOTTA, G.; PEPE, O.; VILLANI, F. Isolation of Saccharomyces cerevisiae strains from different food matrices and their preliminary selection for a potential use as probiotics. J. Appl. Microbiol., v.105, n.6, p.19191928, 2008.

18 REID, A.A.; VUILLEMARD, J.C.; BRITTEN, M.; ARCAND, Y.; FARNWORTH, E.; CHAMPAGNE, C. P. Microentrapment of probiotic bacteria in a $\mathrm{Ca}^{2+}$-induced whey protein gel and effects on their viability in a dynamic gastro-intestinal model. 
J. Microencapsulation, v.22, p.603-619, 2005.

19 RUBIO, M.A. et al . Identificación preliminar in vitro de propiedades probióticas en cepas de Saccharomyces cerevisiae. Rev. MVZ Cordoba, v.13, n.1, p.1157-1169, 2008.

20 RAJKOWSKA, K.; KUNICKA-STYCZYNSKA, A. Probiotic properties of yeasts isolated from chicken feces and kefirs. Pol. J. Microbiol., v.22, n.3, p.257-63, 2010.

21 SUSKOVIC, J.; KOS, B.; GORETA, J.; MATOSIC, S. Role of lactic acid bacteria and bifidobacteria in symbiotic effect. Food Technol. Biotechnol., v.39, n.3, p.227-235, 2001.

\section{AGRADECIMENTOS}

Ao Conselho Nacional de Desenvolvimento Científico e Tecnológico (CNPq) pela bolsa concedida e ao Departamento de Ciência e Tecnologia de Alimentos da Universidade Estadual de Londrina pela realização do experimento. 